\title{
Un mar de soja: la nueva agricultura en Argentina y sus consecuencias ${ }^{1}$
}

\author{
Carlos Reboratti ${ }^{2}$
}

\begin{abstract}
RESUMEN
Entre 1980 y 2005 el cultivo de soja en Argentina se expandió por 15 millones de hectáreas y ese producto y sus derivados pasaron a ser la principal exportación del país. Este crecimiento es el resultado de una compleja trama que combina la potencialidad natural de la región pampeana y las posibilidades de expansión territorial de un nuevo cultivo con los cambios en los mercados mundiales de alimentos, las nuevas tecnologías agrícolas y el papel de las llamadas "nuevas agriculturas". La expansión de la soja tuvo efectos ambientales, sociales y económicos de diversa índole, cuyo alcance y características son actualmente el centro de una acalorada disputa que se ha hecho más dura al incluirse en ella el factor político.
\end{abstract}

Palabras clave: Soja, agricultura argentina, impacto ambiental.

\begin{abstract}
Between 1980 and 2005 soybean production in Argentina grew over 15 million hectares, turning soybean and its derivatives into the principal exportation good of the country. The growth in production was the result of a complex combination between pampa's nature potential and the possibility of territorial expansion of a new crop with changes in the global food market, new agricultural technologies, and the role played by the so called "new agricultures" in underdeveloped countries. This expansion had many environmental, economical and social impacts that gave rise to a heated dispute, which in turn, has become even more complex after the inclusion of the political factor.
\end{abstract}

Key words: Soybean production, argentine agriculture, environmental impact.

Entre 1980 y 2005 la superficie cubierta con el cultivo de soja en la Argentina pasó de 2 a 17 millones de hectáreas. Como consecuencia, este producto llegó a ser la principal exportación del país, ya sea en forma de grano como en sus derivados, por un valor de 8 mil millones de dólares anuales (corresponden $41 \%$ al aceite, $34 \%$ a la harina y $25 \%$ al grano).

Si bien las causas de esta notable expansión se pueden encontrar en una compleja trama que incluye los cambios en los mer-

1 Artículo recibido el 25 de junio de 2009 y aceptado el 14 de septiembre de 2009. cados mundiales, las nuevas tecnologías y el papel que tienen en los países en desarrollo las Ilamadas "nuevas agriculturas" (Kay, 1999), también es importante remarcar que los efectos (ambientales, sociales, económicos y territoriales) de esta expansión son actualmente el centro de una acalorada disputa que se ha hecho aún más dura al incluirse en ella el factor político. En este trabajo se intentará realizar un cuadro del proceso de expansión sojera y sus consecuencias, comenzando por enmarcarlo conceptualmente en el proceso global del cual es parte, pasando luego

\footnotetext{
2 Instituto de Geografía, Universidad de Buenos Aires (Argentina). E-mail: creborat@arnet.com.ar
} 
a analizar sus orígenes y los factores que ayudaron a que el proceso fuera tan rápido, siguiendo con un análisis de las controversias generadas por las interpretaciones del proceso y, finalmente, analizando el posible futuro de esta producción.

\section{El marco global}

A principios de la década de los 90 Eduardo Santos advertía que la creciente inclusión de América Latina en los mercados agroalimentarios internacionales, si bien iba a darle un nuevo impulso al sector agrícola de los países, traería nuevos costos y riesgos, que definía como "... la creciente influencia del capital trasnacional, la dependencia del mercado mundial y la necesidad de operar en mercados cada vez más competitivos..." (Santos, 1992: 336). El proceso de integración de los países de América Latina al mercado internacional de agroalimentos había comenzado efectivamente en la década de los 80 , cuando sus espacios con potencial agrícola, o aquellos donde se generaban producciones tradicionales, comenzaron a formar parte de la escena internacional de intercambio comercial. Esto vino de la mano de varios procesos: los cambios tecnológicos en los sistemas alimentarios; la interconexión creciente entre producción agrícola, industrias y servicios a través de la creación de complejos agroindustriales; las mejoras en los sistemas de transporte y preservación de alimentos; la aparición, por un lado, de nichos de demanda de productos por parte de sectores enriquecidos en los países desarrollados (frutas tropicales, de contraestación, flores) y, por otro, por la irrupción en el mercado internacional de los Ilamados países emergentes que al ritmo de una mejora en los niveles de alimentación de la población comenzaron a aparecer en el mercado internacional como demandantes de alimentos, ya sea para la población como para la cría de animales (McMichael, 2000).

En diferente grado, casi todos los países de América Latina se incluyeron en este proceso, con diversos productos relacionados a los diferentes potenciales ambientales y las distintas estructuras agrarias: frutas en Chile y Brasil, carne en Centroamérica, camarones en Ecuador y, por supuesto, soja en Argentina. Casi siempre este proceso incluyó la ampliación de las áreas productivas o el reemplazo de cultivos y prácticas tradicionales por otras nuevas y diferentes; la introducción de nuevas tecnologías y sistemas de manejo; un creciente uso de insumos de origen industrial; la concentración de tierras y producción y la generación de impactos en el ambiente y la sociedad regional y su organización territorial. Todos estos efectos dieron lugar a su vez a reacciones de diverso tipo, desde las que generaron organizaciones de base étnica o territorial hasta la formación de grupos de opinión de científicos o académicos y la conformación de las ONG que se opusieron al proceso; al mismo tiempo, este fue apoyado por los ideólogos del neoliberalismo, los grupos empresariales más favorecidos, las compañías internacionales productoras de insumos (sobre todo las biotecnológicas) y por los propios gobiernos que los habían promovido o, en el mejor de los casos, simplemente dejado desarrollar sin oponerle mayores trabas ni regulaciones (Solbrig et al., 2001).

Si bien todos los procesos responden a un mismo patrón de desarrollo y a un mismo grupo de causas, en cada caso existen diferencias que lo hacen particular y distinto, como es el de la expansión sojera en la Argentina.

\section{La historia del proceso}

\section{Los orígenes}

Hasta fines de los 80 la producción agropecuaria argentina (y sobre todo la que se desarrollaba en la región pampeana) estaba basada en los cultivos clásicos (maíz, trigo, girasol) y la producción de carne vacuna. Si bien había habido a lo largo del siglo avances de tipo tecnológico, estos se concentraron siempre más en las tareas que en los rendimientos: por ejemplo, la cosecha se había mecanizado, pero casi no se utilizaban fertilizantes; se había introducido el uso de alambrados eléctricos y molinos para manejar la hacienda, pero buena parte todavía pastaba en campos naturales. No completamente, esto hizo que el volumen de producción y los rendimientos crecieran muy despacio, y en ese sentido el país había ido perdiendo preeminencia en los mercados internacionales y quedando retrasado con respecto a los avances 
en productividad (Barsky y Gelman, 2001). Sin embargo, el uso mesurado de los recursos y una cierta alternancia entre diferentes cultivos y la ganadería había preservado en buena medida la calidad de los suelos. A través de décadas de fragmentación por herencia de las grandes estancias originales, y el papel que habían tenido en buena parte de la región pampeana, los esquemas de colonización por productores familiares (conocidos como chacareros), la tierra estaba distribuida en forma relativamente equitativa, lo que no había impedido un proceso de fuerte emigración de la población rural, sobre todo la dispersa (Balsa, 2006). Paralelamente, esta estructura agraria había dado lugar a una organización territorial basada en las líneas de ferrocarril (más tarde reemplazadas con la misma geometría por caminos) y una cantidad de pequeños pueblos y ciudades medianas fuertemente ligados a la producción agropecuaria.

Fue en ese marco que comenzaron a llegar algunos de los adelantos tecnológicos impulsados por la llamada "revolución verde", principalmente dos: el uso de nuevas variedades más productivas y la aplicación de agroquímicos, que mejoró, sobre todo, la situación de la producción de trigo y maíz (Obstchatko, 1988). Fue justamente la aparición de trigos de origen mexicano, de ciclo más corto que los tradicionales, lo que permitió pensar en una utilización más intensiva del suelo, a través de la introducción de dos cosechas anuales, una de invierno y la otra de verano. Y la soja parecía como la más adecuada para cumplir el segundo rol, un cultivo que se podría sembrar en los campos donde recién se había cosechado trigo, pero que requería el uso de fertilizantes en suelos que estaban ya en su límite agronómico de productividad natural y que, además, casi no tenían descanso a lo largo del año (Morello y Solbrig, 1997).

La soja apareció en la región pampeana en un contexto muy favorable para su desarrollo: esta región se encontraba en medio de un ciclo húmedo, con relativamente pocas variaciones interanuales en las precipitaciones (la larga sequía de 2008-09 fue totalmente excepcional) y sin las grandes inundaciones que habían caracterizado el oeste de la región a principios de la década de los 80 . Los precios internacionales se mantuvieron altos, con una tendencia al aumento y relati- vamente pocas variaciones, y en el mercado internacional apareció un comprador, China, que se transformó rápidamente en el cliente más importante de los productores sojeros, un comprador que estaba dispuesto a aumentar continuamente sus adquisiciones (dedicadas a alimentar los cerdos) y que no ponía reparos en cuanto al origen tecnológico del producto. La posterior aparición potencial de un mercado para los biocombustibles afianzó aún más el precio de la soja, que recién tuvo una caída con la crisis de 2008. Y los problemas de transporte interno que clásicamente habían tenido los granos en la Argentina fueron en buena medida solucionados por una mayor capacidad de retención de la cosecha por los productores (se volverá sobre este tema) y también debido a la aparición en las cercanías de las áreas productoras de una densa red de puertos privados, pequeños y muy eficientes por la adopción de modernas tecnologías de embarque (Figura $N^{0} 1$ ). Nada parecía ser capaz de limitar la producción sojera, que se expandió por buena parte del país (Bisang y Gutman, 2003; Bisang, 2008; Reca y Parellada, 2001).

\section{La expansión territorial}

Debido a que el límite territorial de la agricultura pampeana de secano había sido alcanzado hacia los primeros años del siglo $X X$, cualquier expansión de un nuevo cultivo en esa región debía hacerse de la mano del reemplazo de otros usos o -como en el caso de la dupla trigo-soja- por su superposición espacial. La soja significó la reducción o estancamiento de la superficie dedicada a otros productos agrícolas y el reemplazo de las dedicadas a la ganadería. Así fue que el trigo y el maíz se mantuvieron aproximadamente con las mismas áreas que antes, pero por un notable aumento de su productividad eso no se tradujo en una disminución del volumen producido: muy por el contrario, este aumentó. En cambio otros cultivos, como el girasol, redujeron fuertemente su superficie. Pero donde realmente la soja suplantó agresivamente a otra actividad fue en las áreas dedicadas a la ganadería, tanto vacuna como ovina. En el primer caso, la necesidad de mantener los stocks llevó a los productores a adoptar dos estrategias distintas: una fue desplazarse hacia las provincias marginales de la región pampeana, la otra fue la concentración del rebaño 
en feed lots, en los que los animales se mantenían en un mismo lugar, no pastoreaban y se les llevaba el alimento y el agua.

La producción ovina, en cambio, al enfrentarse al mismo tiempo con la presión de la soja y una crisis de los precios internacionales, simplemente redujo su stock. En la región pampeana, el número de cabezas de vacunos disminuyó desde los inicios de la expansión en no menos de 4 millones de cabezas, mientras que los ovinos lo hacía en poco menos de dos millones, lo que en conjunto liberó las más de 4 millones de hectáreas que requería la soja además de desplazar a algunos cultivos.

Figura $N^{\circ} 1$

La expansión de la soja en Argentina

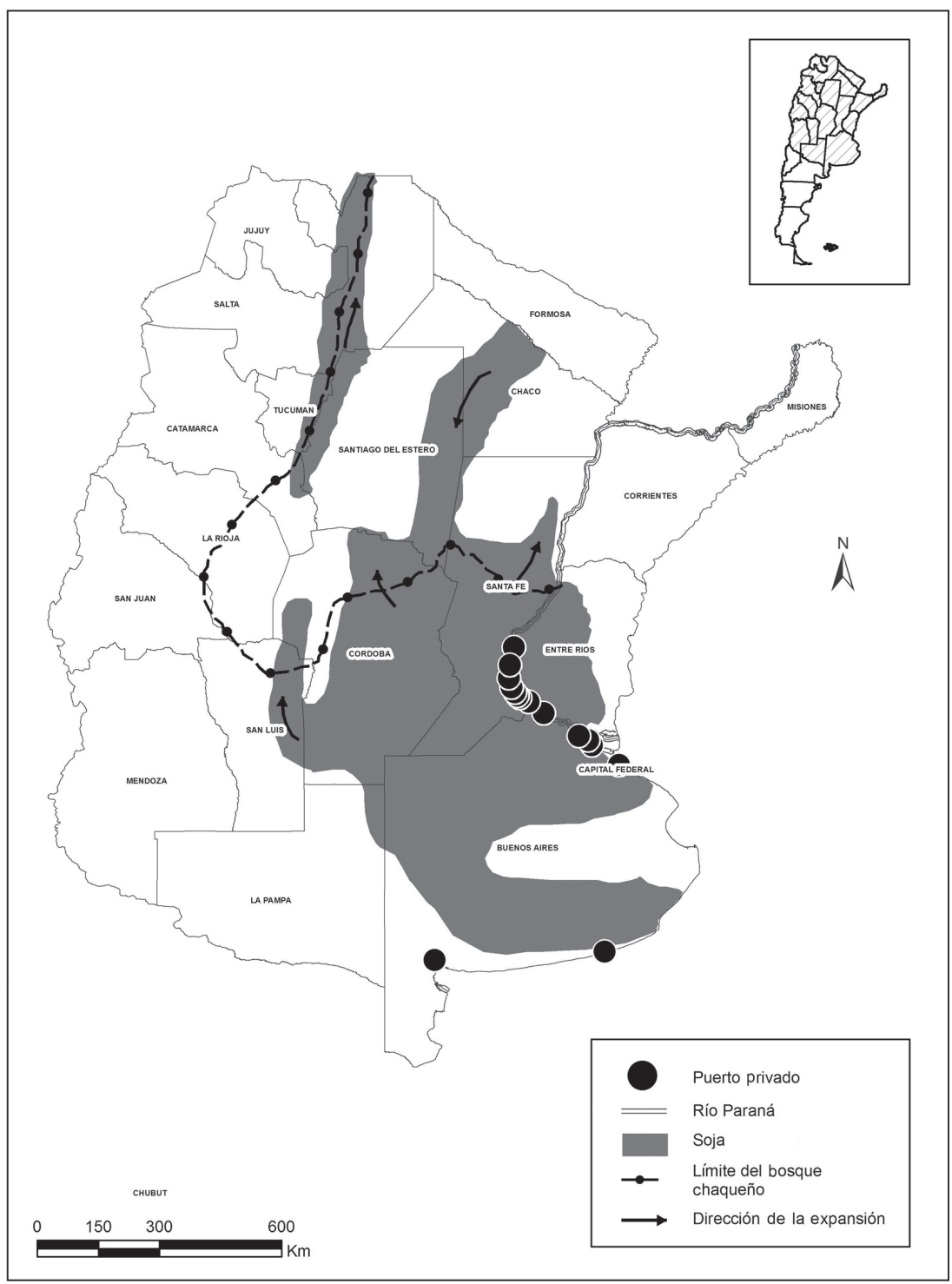

Fuente: Elaboración propia. 
Desde el punto de vista de la organización territorial, la soja simplemente en la región pampeana se superpuso a la ya existente estructura, basada en una red densa de transportes y centros urbanos pequeños y medianos. Estos fueron los más favorecidos por la expansión sojera, al albergar por una parte a los propietarios que decidieron alquilar sus tierras $y$, por otra, al desarrollarse una cantidad de servicios agrícolas de base urbana.

La dinámica de reemplazo territorial caracteriza a la primera etapa de la expansión sojera. Pero hacia mediados de los 90 el efecto del aumento del precio de los arriendos rurales (y por lo tanto del precio de la tierra) fue tal que muchos productores pampeanos comenzaron a buscar nuevas tierras, y fue entonces que se produjo una expansión del tipo de "frontera agraria" hacia los campos de las provincias del norte. Aquí la expansión significó al mismo tiempo el reemplazo de los cultivos más tradicionales (algodón en el Chaco, poroto en el noroeste) y la deforestación del bosque original, hasta ese momento utilizado para ganadería extensiva y la extracción de madera. En el norte del país la expansión de la soja ocupó en pocos años más de 1,6 millones de hectáreas (a lo que suma una mayor producción de trigo y girasol que cubrieron otras 577.000), superficie que fue en parte sustraída de las producciones tradicionales (casi 500.000 hectáreas), por una reducción en el número de vacunos (cerca de un millón) y de la deforestación, que llegó entre 1995 y 2005 a no menos de un millón de hectáreas (Azcuy Ameghino y León, 2005; Adámoli, 2008; Grau et al., 2008).

Pero es difícil no tratar de cambiar de escala y ver la expansión territorial de la soja como un tema que va más allá de las fronteras de la Argentina. En realidad el proceso había comenzado en el sur del Brasil en la década de los 70, y a partir de allí avanzó hacia el norte, alcanzó el estado de Mato Grosso a principios de los 90 y continuó hacia el norte y el nordeste (Warnken, 1999). Paralelamente, la producción se expandió por el este de Bolivia y Paraguay, y produjo en este último país una de las deforestaciones más rápidas y extensas que se conozcan (Kholhepp, 1999; Dros, 2006; Kaimowitz et al., 1999). A la formación de lo que una compañía multinacional de agroquímicos Ilama "la república de la soja", contribuyeron también los productores argentinos, que se expandieron en Paraguay y Bolivia, y últimamente en Uruguay.

\section{Las nuevas tecnologías}

Una de las características más notables de la expansión sojera es que generó en los productores agrícolas una nueva capacidad de adopción de tecnología en un medio que hasta el momento había mostrado una actitud relativamente conservadora al respecto. Estos cambios tecnológicos se centraron en tres aspectos: el uso de semillas transgénicas, la labranza cero y siembra directa y los sistemas de almacenamiento.

La internacionalización de la agricultura masiva de los 90 vino de la mano de un nuevo impulso en las modificaciones de los productos agrícolas, en este caso por la adopción de técnicas de la llamada "ingeniería genética" que introducían en los cultivos experimentados una serie de rasgos que se consideraban positivos para una mayor eficiencia productiva de los mismos: rechazo a plagas, mayor vigor para soportar herbicidas, mejoras en la calidad alimenticia, entre otros (Yapa, 1993). Aunque en un principio de esta nueva revolución verde se suponía que tenía la ventaja de ser una tecnología que se podría producir en centros de investigación pequeños, como por ejemplo las universidades (Sorg y Wilkinson, 1994), a poco avanzar el proceso se vio claramente que las mayores beneficiarias serían las grandes compañías internacionales de agroquímicos, que además se apropiaban de las patentes de esos productos (Pringle, 2003; Trigo et al., 2002). Entre esos experimentos se encontraba la producción de semillas para la llamada "soja RR", resistente al glifosato, un herbicida de amplio espectro, de bajo precio en el mercado y que hasta el momento no se podría utilizar en la soja por carecer de resistencia al producto. Si bien, y como veremos más adelante, el uso de estas semillas trajo mucha resistencia en el resto del mundo, los productores argentinos lo adoptaron con una celeridad pasmosa, y en pocos años casi el $90 \%$ de la soja que se cultivaba era del tipo RR (el porcentaje más alto de adopción en todo el mundo). 
La ventaja para el productor era que reducía el costo de uso de herbicidas y además exigía solo una fumigación, lo que también disminuía el costo total. Si bien Monsanto, la compañía propietaria de la patente, pretendía que la semilla se comprara para cada cosecha, como la soja RR transmite sus características a su descendencia, los productores argentinos simplemente comenzaron a utilizar su propia semilla, o compraban la de otros productores, para desesperación de esa compañía (que además no podía iniciar acciones legales contra los productores ya que no había podido patentar la semilla en el país).

En paralelo a la utilización de la semilla genéticamente modificada, otra tecnología se extendió por el área sojera: la labranza cero con siembra directa. Esta era una tecnología originariamente norteamericana que ya se conocía en el país desde la década de los 80 , pero que recién con la soja se popularizó. Se trata simplemente de sembrar la semilla directamente sobre los restos de la cosecha anterior, sin dar vuelta la tierra ni removerla. Esto por una parte reduce el impacto de la erosión hídrica y eólica en el suelo, que permanece cubierto todo el año, no limita la reproducción de la microfauna y retiene en el suelo la humedad por mayor tiempo. Como contracara, dado que no se eliminan los residuos de otras cosechas, esto genera una mayor presencia de malezas y pestes, las que a su vez son combatidas mediante la aplicación de mayor cantidad de agroquímicos. Esta tecnología también reduce los costos generales de producción y además tiene un tinte conservacionista - de los suelos solamente-, por lo cual también fue rápidamente adoptada por los productores de soja.

Los sistemas clásicos de almacenaje para la producción agrícola eran hasta hace no muchos años muy primitivos o directamente inexistentes, lo que obligaba a los productores a enviar su cosecha para la venta o el almacenaje de terceros a medida que esta se realizaba, lo que, o elevaba los costos de producción, o bien ponía a los productores a merced de los precios del momento, sin posibilidades de esperar por otros mejores. Esto en buena medida fue solucionado por la aparición de los llamados silos bolsa, que son simplemente grandes tubos de plástico que se ubican en trincheras en el suelo y se llenan de grano, en los cuales se puede controlar el tenor de humedad y realizar un control de plagas. Y por sobre todo posibilitó a los productores retener en el campo la cosecha una vez que esta se había realizado, lo que les permitía esperar mejores precios y además tendía a no saturar los sistemas de transporte y embarque. Esta nueva tecnología, junto con la aparición ya mencionada de los puertos privados en la ribera del río Paraná, solucionó el problema del embarque de la nueva producción.

\section{Los nuevos productores y el complejo agroindustrial}

La expansión sojera, por el contexto económico y político en la cual se desarrolló y la forma en que fue planteada, requirió una modificación de los actores involucrados en la producción agrícola y de los procesos de organización de la misma. Estos actores -tanto los nuevos como los antiguos que modificaron sus sistemas productivos- se alinearon en la idea del agrobusiness, esto es, en sistemas agrarios de producción empresarial que se concentraban en la rotación del capital y su desplazamiento de fijo a variable, la búsqueda de beneficios rápidos, el uso de la tecnología para reemplazar mano de obra y, en este caso específico, el abandono de la idea de apropiación permanente de la tierra y su reemplazo por el alquiler temporario. Como resultado de estos cambios, creció enormemente la terciarización de los servicios productivos, como la siembra, la fumigación y la cosecha, y apareció con fuerza el Ilamado contratista, una empresa que posee maquinarias de todo tipo y que recorre los campos ofreciendo sus servicios. En paralelo creció el peso del arriendo en la estructura agraria: para mediados de la década del 2000 ya el $60 \%$ de la soja pampeana se producía en tierras alquiladas para ese fin.

La producción sojera se desarrolló mediante diferentes combinaciones de los factores de producción, y en la realidad aparecen todo tipo de arreglos con respecto a la tenencia de la tierra y la posesión de maquinarias. La más novedosa fue la aparición de los Ilamados pools de siembra, en la práctica la unión de capitales de diferente origen y tamaño (financiero, industrial, agrícola) que se reúnen para alquilar campos y producir 
utilizando el sistema de contrato; y los llamados fideicomisos, donde un gran productor o capitalista asocia capitales pequeños para aumentar su escala de producción.

La inversión de capital necesaria, el costo y tamaño de las maquinarias y el progresivo aumento del precio de la tierra (ya sea para compra o para arriendo) hizo crecer el tamaño mínimo a partir del cual se podía encarar la nueva producción y también generó un proceso de urbanización del campo, ya que no solo los productores que antes vivían en él se seguían mudando a las ciudades cercanas (como lo venían haciendo por lo menos desde la década de los 60), sino que aparecieron productores de origen urbano, interesados en la rentabilidad de la producción agrícola. Todo esto generó un aumento en el tamaño medio de la producción y la aparición de muy grandes conglomerados, que llegan a administrar la producción de centenas de miles de hectáreas, distribuidas no solo en la región pampeana, sino también en el norte y aun en los países vecinos.

Al mismo tiempo que se ampliaba la producción, esta se insertaba en un sistema agroindustrial complejo, que incluía, por un lado, a los productores y comercializadores de insumos $y$, por otro, a los fabricantes de aceite y los exportadores. Este complejo agroindustrial reforzó la trama territorial ya existente, al encadenar procesos, desde la producción de insumos hasta la industrialización del grano, en una serie de instalaciones ubicadas algunas en el medio rural (por ejemplo, las semilleras), en lo pueblos más pequeños (los comercializadores de insumos) y en las ciudades más grandes (industria aceitera y de maquinarias).

La expansión sojera no hubiera sido posible si no hubiesen aparecido los insumos necesarios: por una parte los agroquímicos, por otra, las maquinarias. En el primer caso el campo argentino entró en la órbita de las grandes compañías internacionales de agroquímicos, fuertemente concentradas y que ofrecen en el mercado fertilizantes, herbicidas, pesticidas e inocultantes para asegurarle al productor el más alto rendimiento posible, aunque como contracara lo mantienen atado a un círculo de compra constante de insumos para mejorar su competitividad y, por lo tan- to, a la necesidad de buscar crédito para las tareas de siembra.

Un segundo grupo de insumos, menos concentrados económicamente, es el de las fábricas de maquinaria agrícola. En ese rubro Argentina ha tenido una larga historia de participación en la innovación tecnológica y la producción de arados, sembradoras y cosechadoras. La expansión sojera dio mucha vitalidad a esa industria, distribuida en las ciudades medianas de toda la región pampeana y que contrata a gran cantidad de empleados. La producción y comercialización de insumos ha sido un factor muy importante en la reactivación de la población urbana regional, y en buena medida explica el fuerte apoyo que el campo tiene en el conflicto con el gobierno nacional, que se verá más adelante.

En el otro extremo de la cadena, los productores podían elegir vender su cosecha a las fábricas de aceite de soja o dirigirlos a la exportación. Estos dos eslabones estuvieron desde un principio muy concentrados: las fábricas de aceite en grandes plantas generalmente de capitales nacionales (hay alrededor de 50), mientras que los canales de exportación quedaron en manos de las clásicas firmas internacionales de comercialización de granos, como Dreyfus, Cargill o Bunge y Born.

\section{Soja y política}

Prácticamente desde el comienzo del proceso expansivo de la soja el gobierno había tenido una actitud implícitamente positiva hacia el mismo: había aprobado las nuevas variedades y las oficinas técnicas oficiales generalmente acompañaban el proceso con investigación y recomendaciones sobre distintos aspectos productivos a través de la extensión agropecuaria.

Fundamentalmente, y en forma creciente, el gobierno venía extrayendo una buena parte de las ganancias producidas por la soja a través de la imposición de las retenciones a las exportaciones, que se cobraban en los puertos de embarque y de esa manera evitaban al gobierno la necesidad de controlar a los productores en el campo. Estas retenciones para fines de 2007 significaban más del $30 \%$ del precio, lo que llevaba a las arcas 
oficiales 1.500 millones de dólares anuales. Pero ante el aumento internacional del precio de la soja y las necesidades de ingresos de divisas, en forma sorpresiva el gobierno en marzo de 2008 decretó un aumento de las retenciones a más del $40 \%$ y determinó que estas serían progresivamente mayores a medida que aumentaba el precio internacional. Esto generó un fuerte rechazo en los productores, a través de las diferentes asociaciones que los agrupaban, que llevó a las distintas asociaciones a reunirse en la llamada mesa de enlace. Esta comenzó a presionar al gobierno para que derogara el decreto e iniciara un proceso de negociación, sin embargo, ante la falta de respuesta concreta decidieron realizar una serie de paros de actividades y cortar temporariamente algunas rutas (una metodología que se inició en el país a mediados de los 90 cuando grupos de desocupados, denominados piquetes, cortaban las rutas pidiendo por sus puestos de trabajo). Su capacidad de convocatoria se vio claramente cuando en un momento dado había más de 400 piquetes cerrando las rutas del país, muchos de ellos espontáneos. A medida que el conflicto se alargaba, y para reforzar su posición, el gobierno nacional iba tomando una actitud cada vez más contraria a la producción sojera, Ilegando la propia Presidenta a calificar despectivamente a la soja como un yuyo (nombre local dado a las malezas). La confrontación continuó cada vez con mayor fuerza, y en ocasión de la celebración del 25 de Mayo (cuando se festeja la revolución de 1810), mientras la mesa de enlace convocaba a 200.000 personas en Rosario, el gobierno apenas pudo congregar 50.000 en la ciudad de Salta, lo que indica la fuerza que había adquirido el movimiento del campo. Presionados por sus bases políticas, varios gobernadores provinciales, legisladores nacionales y muchos intendentes de pueblos y ciudades adhirieron a la protesta. Al persistir la presión por derogar el decreto, el gobierno se vio obligado a enviarlo al Congreso, para legitimarlo y que tuviera fuerza de ley; finalmente el decreto fue rechazado, lo que obligó al gobierno a anularlo. A partir de allí el campo pasó a ser un elemento importante en el juego político nacional, dado que la cerrada negativa del oficialismo a negociar con los agricultores había generado un fuerte rechazo en toda la región pampeana; de hecho, la mesa de enlace se constituyó en una fuerza opositora al gobierno nacional y con un peso propio en las negociaciones políticas, aunque sin relaciones muy definidas con los partidos políticos tradicionales (Barsky, 2008).

\section{Las consecuencias y las críticas al proceso}

Un proceso de tanta amplitud y dinámica como la expansión sojera que hacia 2007 incluía más de 70.000 productores que cultivaban unos 15 millones de hectáreas y producían no menos de 47 millones de toneladas, cuya exportación significaba 15.000 millones de dólares, necesariamente debía generar reacciones en la sociedad argentina, las que están representadas en una confrontación entre interpretaciones diferentes sobre sus consecuencias, tanto las ambientales como las económicas y sociales. Con la aparición en el 2008 de una nueva dimensión -la política- esta confrontación se hizo aún más acentuada.

Los temas alrededor de los cuales se han producido las mayores controversias son: los efectos del monocultivo sobre el ambiente, la sociedad y la economía, el potencial efecto del uso de semillas genéticamente modificadas y del glifosato y el problema de la deforestación. A continuación se analizarán estos temas, contraponiendo las distintas posiciones.

\section{Los efectos del monocultivo}

La aparición y posterior expansión de la soja en la región pampeana significó el congelamiento de la antigua alternancia de ciclos agrícolas y ganaderos, reemplazados por una agriculturización permanente $y$, dentro de este proceso, una tendencia a la monoproducción generada por la alta rentabilidad relativa de la soja con respecto a otras posibles producciones. Como cualquier otro cultivo, la producción constante de soja sobre un mismo campo genera a la larga una disminución selectiva de los nutrientes que más utiliza ese producto, lo que llevado a su extremo puede generar el agotamiento del suelo y la necesidad de agregar cada vez más fertilizantes. Desde ese punto de vista, la rotación con otros cultivos y la alternancia con largos períodos de descanso siempre se ha 
tomado como la solución más adecuada. Sin embargo -y este es un caso muy claro-, esa posibilidad choca con dos elementos limitantes: primero, que durante varios años las ganancias por la producción sojera han sido tan diferenciales que muchos productores, aun sabiendo el daño que el monocultivo podía generar en el suelo, siguieron produciéndola continuamente; segundo, que la posibilidad de rotación se hace más remota cuando buena parte de los suelos productivos se trabajan bajo la forma del arriendo. El arrendatario capitalista, de acuerdo a su racionalidad, por supuesto intentará que, en el periodo que arrienda, los productos que obtenga sean los más rentables.

Este efecto edafológico del monocultivo ha sido señalado repetidamente por los críticos al proceso sojero (Pengue, 2000) y sus promotores no han tratado de negarlo, adoptando dos posiciones, la primera es que el nivel de utilización de fertilizantes en la producción sojera es todavía muy bajo con respecto a países como Estados Unidos, lo que le daría a la elaboración cierto margen antes de llegar a una situación crítica, y la otra, más fatalista, es que en un país donde los productores no reciben subsidios estatales que les permitan hacer cultivos más rentables, el mercado les impide hacer otra cosa. En este tema se ve claramente la ausencia de capacidad regulatoria por parte del Estado, ya que en Argentina el suelo es de propiedad privada y su manejo no está sujeto a reglamentación alguna, sino a lo sumo podría responder a las recomendaciones no obligatorias que se puedan hacer. Distinto es el caso del arriendo, que siendo una transacción entre actores, puede ser regulada por el Estado (como lo han sido históricamente los arriendos a pequeños productores). Pero aquí aparece una segunda incongruencia: el gobierno nacional, en su posición antisoja, no impulsa la aprobación de una ley de arriendos (que hace años está en el Congreso) dirigida a fijar un plazo mínimo de arriendo (tres años) y obliga a la rotación de cultivos.

La predominancia de la soja ha generado por parte de sus críticos dos cuestiones: el éxodo rural y la reducción del empleo. Estas opiniones dicen que la soja, por su alto nivel de tecnificación y su tendencia a la concentración de tierras, ha acelerado el despoblamiento del campo y ha reducido el número de trabajadores empleados (GRR, 2002; Teubal, 2006). En relación al éxodo rural, en realidad no está muy claro si la soja ha iniciado o acelerado este proceso; el campo argentino, y también el pampeano, se ha venido despoblando desde por lo menos la década del 30, cuando las ciudades aparecieron como generadoras de mejores condiciones de trabajo y servicios en los sectores secundario y terciario, mientras que esas condiciones en el campo no cambiaban o desmejoraban. Desde ese punto de vista, la soja no inició el proceso y es discutible que lo hubiera agudizado, dado que ya en la década de los 80 el número de pobladores rurales dispersos era muy bajo. Por otra parte, los pequeños y medianos propietarios, que han elegido arrendar sus campos a los productores de soja (una solución racional teniendo en cuenta el altísimo nivel de los arriendos), se trasladan a las ciudades pampeanas, en las cuales es evidente un efecto muy positivo del ingreso de migrantes con una renta alta, a lo que se suma la instalación en esos pueblos y ciudades de toda una cantidad de actividades relacionadas directa o indirectamente con la producción rural: servicios como talleres mecánicos y empresas de computación, comercio de insumos agrícolas, entre otros. Todo este conjunto de nuevas actividades ha generado un renacimiento en esas localidades, cuyos pobladores sin duda asignan al mágico efecto soja.

Con respecto al empleo, hay que tener en cuenta dos factores: uno es que el reemplazo de mano de obra por maquinarias viene sucediendo en el campo pampeano (y también en las otras regiones) por lo menos desde fines del siglo XIX, cuando las trilladoras reemplazaron a los miles de trabajadores migrantes que empleaba la cosecha del trigo, en ese momento el principal producto de exportación (y que había tenido un proceso de expansión fulminante muy similar, en su contexto histórico, al de la soja) (Scobie, 1968). En pasos sucesivos se mecanizó la cosecha, el arado, la siembra y el combate de las malezas, y cada vez los requerimientos de mano de obra se reducían. En verdad, nadie podría pensar hoy que una producción masiva se podría hacer sin la ayuda de la mecanización, y era evidente que, desde ese punto de 
vista, la soja no iba a producir una expansión de la demanda de trabajo. Pero, sin embargo, algunos comentaristas apuntan a que no es posible mirar la cadena de producción de la soja sin considerar la totalidad de la misma, y que si se considera el empleo total, los números son considerablemente más altos que si solo se toma en cuenta el eslabón agrícola (Llach, 2004).

\section{La soja $R R$ y el glifosato}

Como se ha visto, uno de los factores que más ha dinamizado la expansión de la soja en Argentina es la rápida adopción por parte de la gran mayoría de los productores de las semillas genéticamente modificadas $y$, en consecuencia, el uso del glifosato como herbicida. En consonancia con la posición adoptada por el ambientalismo internacional, en el país comenzaron a surgir críticos a esa adopción tecnológica, que se podría pensar en dos vertientes: una relacionada a la propia semilla, la otra al uso del glifosato (Otero, 2008; Paul y Steinbrecher, 2003; Branford, 2004).

Las críticas a la semilla se centraron básicamente en los potenciales peligros que podría tener la soja transgénica para la salud humana en el largo plazo y en la posibilidad de que la fuerza genética de ese cultivo pudiera transmitirse a otras especies, creando las supermalezas, resistentes a su vez al glifosato (Pengue, 2005). Ante estas críticas, los promotores de la soja advirtieron que ese producto había sido permitido en el país luego de un cuidadoso análisis por parte del organismo oficial certificador, que a más de doce años de plena producción nunca se habían advertido efectos nocivos en la salud humana y que tampoco se podía probar -salvo en algunos casos aislados- que pudiera haber derivas genéticas de la soja a otras especies (Autores varios, 2005). El sector estatal no intercedió en la disputa, aunque el Ministerio de Agricultura respondió negativamente a una presentación de Monsanto con respecto a los derechos de uso de la semilla, dando de ese modo respaldo explícito al producto.

El uso del glifosato también despertó críticas entre los grupos ambientalistas, acusando a Monsanto de vender un producto peligroso para la población y la biodiversidad y que contaminaba el suelo y el agua. Estas críticas mezclaron dos temas diferentes: las características del producto y las consecuencias de su uso inadecuado, lo que en alguna medida debilitó el argumento. Sobre las características del mismo, tanto el gobierno como las corporaciones de agricultores y por supuesto las compañías productoras, señalaron que era un producto inocuo y que no se transmitía ni al suelo ni al agua una vez fumigado, pero en una típica situación de falta de legitimidad de la ciencia como árbitro de este tipo de situaciones (Ozawa, 1996), los críticos presentaron a su vez trabajos de investigación donde se señalaba que el glifosato podía tener consecuencias en la salud y que sí se transmitía por los ecosistemas. En una maniobra con claro sentido político, el Ministerio de Defensa prohibió el uso de ese producto en los campos de su propiedad, pero la falta de pruebas contundentes hizo que la controversia no tuviera mayores resultados entre los productores y no se tomaron medidas generales sobre el empleo de ese herbicida.

Si consideramos la actitud de los grupos críticos al proceso, es notable la diferencia que existe entre su capacidad de llegada al público en general (y sobre todo a las clases medias), que por lo menos en Argentina tiende a considerar siempre como ciertas a las posiciones más pesimistas y catastróficas, $y$ el efecto que han tenido sobre los propios productores sojeros, que directamente no las han tenido en cuenta. Esta falta de diálogo se basa en un factor que pareciera de suma importancia: los críticos a la soja (una mezcla de grupos ambientalistas nacionales e internacionales, investigadores científicos y representantes de pequeños productores y campesinos) no proponen ninguna solución alternativa realista a los cientos de miles de agricultores, transportistas, trabajadores en los servicios y las industrias directamente ligados a ese producto, por lo cual sus opiniones son tomadas como irreales o ideológicamente sesgadas. Demonizar a la soja y sus productores no parecería ser un buen camino para solucionar los problemas que aparentemente se han encontrado.

Por su parte, también hay que tener en cuenta que los grupos promotores de la 
producción sojera (corporaciones de productores, grandes empresas productoras de insumos) son muy poderosos y tienen acceso a los medios masivos de comunicación: por ejemplo, los suplementos semanales de temas rurales de los dos diarios de mayor importancia en Argentina son evidentemente pro soja, y son esos mensajes los que llegan con más facilidad a los actores directamente involucrados en la producción; se podría decir que ese mensaje se ha montado en el éxito de la producción. De la misma forma que el público en general acepta sin mayores recaudos las posiciones más pesimistas, los que se han beneficiado no están dispuestos a escuchar críticas.

\section{La deforestación}

Mientras la soja se mantuvo dentro de la región pampeana (un ambiente naturalmente carente de árboles), la controversia sobre su producción se centró en el tema de los efectos contaminantes de su producción. Sin embargo, a medida que el cultivo se expandía hacia el norte, buscando tierras más baratas, comenzó a aparecer un nuevo efecto, esta vez sobre el bosque nativo que cubría buena parte de la Argentina subtropical. Hasta el momento no existía en el país un sistema realmente efectivo de regulación de la deforestación, y la gran masa forestal del país -aún muy disminuida desde su extensión original- se mantenía como una reserva importante de recursos naturales. Habían sido relativamente pocos los cultivos que competían con el bosque en el uso del suelo: el algodón en el Chaco, la yerba mate y el té en Misiones, la caña de azúcar y el poroto en el noroeste. Esto no significaba que el bosque se hubiera mantenido intacto, ya que su uso como área de pastoreo y la explotación selectiva de la madera lo habían degradado, pero no eliminado totalmente.

Pero la soja avanzó muy agresivamente sobre los remanentes del bosque, auspiciada muchas veces por los gobiernos provinciales que extendían muy fácilmente permisos de desmonte. Hacia 2007, la situación se estaba agravando y por primera vez se podía notar un efecto ambiental claro relacionado con la producción sojera. Aprovechando en algunos casos situaciones dudosas de la tenencia de la tierra, en otros comprando o arrendando grandes superficies a sus dueños titulares y aun en otras comprando tierras fiscales que el Estado vendía, los grandes productores pampeanos (y algunos locales) tomaron su control y desmontaron enormes superficies con el uso de maquinaria pesada. Esto no solo produjo un efecto ambiental, sino también social, dado que muchas de esas nuevas tierras estaban ocupadas desde hacía mucho tiempo por grupos aislados de campesinos e indígenas que fueron expulsados. Varias de sus organizaciones de base, así como ONG que los apoyaban protestaron fuertemente, si bien nunca se llegó realmente a poder organizar una protesta consistente (Slutsky, 2005).

Fue allí cuando en el Congreso se comenzó a debatir una ley de manejo forestal, que luego de mucha discusión se promulgó a fines de 2007, pero recién se reglamentó un año más tarde. Sin embargo, y sobre todo en la provincia de Salta, los desmontes continuaban, amparándose en los permisos que la provincia había otorgado antes de la ley. Finalmente, y frente a una presentación de los grupos indígenas, en marzo de 2009 la Suprema Corte emitió un decreto prohibiendo todo desmonte hasta que la provincia cumpliera con la ley en lo que respecta a generar un plan de ordenamiento territorial forestal que marcara con claridad qué área y bajo qué condiciones se podía eliminar el bosque para dedicarlo a la agricultura.

Si bien este tema fue objeto de mucha promoción pública, salvo en muy pocos casos la ley forestal no tuvo una reacción abierta de las agrupaciones de productores, aunque su presión fue muy evidente en el momento en el cual la ley se estaba debatiendo y por el largo tiempo pasado hasta su reglamentación. No obstante, la aplicación de la ley no significa que la expansión sojera terminara: cumpliendo con lo pedido por la ley, las provincias del norte están marcando no menos de 5 millones de hectáreas como potencialmente disponibles para la producción agrícola, si bien no todas ellas son potencialmente aptas para el cultivo de secano.

La discusión sobre la deforestación atrajo también la atención sobre los efectos territoriales de la producción sojera en el norte 
del país, fundamentalmente sobre el noroeste. En esta región no existía una red densa de localidades urbanas como en la región pampeana y la expansión agrícola produjo una cierta modificación en la estructura territorial: por una parte, la red de caminos se hizo más densa y aparecieron en lugares estratégicos algunos pueblos, como Las Lajitas, que crecieron al concentrar las funciones de servicios para la nueva producción; por otra, en el noroeste la expansión se hizo en base a grandes unidades productivas, que no solo empujaron la deforestación, sino que también entraron en conflicto con los grupos campesinos y de pobladores originarios que vivían en el medio rural sin poseer títulos legales sobre la tierra.

\section{Consideraciones finales}

Todo indica que la soja llegó a la Argentina para quedarse y que en el futuro su predominio se extenderá aún más. Por ejemplo, la prolongada sequía entre 2008 y 2009 redujo las posibilidades de siembra de trigo, lo que lleva a los productores a volcarse todavía más a la soja. Por otra parte, después de la caída de precios por la crisis internacional, los correspondientes a la soja han aumentado en forma sostenida, y China se mantiene como un comprador muy activo. La crisis política alrededor del "conflicto del campo" no ha resultado en ninguna medida para limitar la producción de soja y los grandes productores parecieran afianzarse en su posición. Si bien la expansión en Paraguay y Bolivia fue promovida en un principio por productores brasileños, hoy en día es común que productores argentinos cultiven campos en esos países y ahora también en Uruguay y que se generen joint ventures entre productores brasileños y argentinos con vista a una expansión aún mas rápida del cultivo. Desde el punto de vista territorial, todavía en la región pampeana la soja podría avanzar considerablemente sobre las tierras ganaderas y existe una reserva importante de tierras en el norte, si bien aquí la expansión podría generar conflictos tanto de tipo social como ambiental. El reinado de la soja, que ha puesto a esa república virtual al tope de las áreas productoras mundiales de alimentos, pareciera no tener límites.

\section{Referencias bibliográficas}

ADÁMOLI, J. y SOLBRIG, O. (coord.). Agro y ambiente: una agenda compartida para el desarrollo sustentable. Buenos Aires: Foro de la Cadena Agroindustrial Argentina, 2008. Disponible en Internet: http://www. foroagroindustrial.org.ar/home.php

Autores varios. La transformación de la agricultura argentina. Ciencia Hoy, 2005, vol. $15, N^{\circ} 87$, p. 1-60.

AZCUY AMEGHINO, E. y LEÓN, C. La sojización: contradicciones, intereses y debates. Revista Interdisciplinaria de Estudios Agrarios, 2005, № 23, p. 133-158.

BALSA, J. El desvanecimiento del mundo chacarero. Transformaciones sociales en la agricultura bonaerense 1937-1988. Buenos Aires: Editorial de la Universidad Nacional de Quilmes, 2006.

BARSKY, O. y DÁVILA, M. La rebelión del campo. Historia del conflicto agrario argentino. Buenos Aires: Sudamericana, 2008.

BARSKY, O. y GELMAN, J. Historia del agro argentino. Buenos Aires: Grijalbo Mondadori, 2001.

BISANG, R. et al. Un revolución (no tan) silenciosa. Claves para repensar el agro en Argentina. Desarrollo Económico, 2008, vol. $48, N^{\circ} 190-91$, p. $165-208$.

BISANG, R. y GUTMAN, G. Un equilibrio peligroso. Nuevas dinámicas en la producción agropecuaria. Encrucijadas, 2003, vol. 3, № 21, p. 8-19.

BRANFORD, S. Argentina's bitter harvest. New Scientist, 2004, vol. 182, № 2443, p. 1-4.

DROS, J. Manejo del boom de la soya: dos escenarios sobre la expansión de la producción de la soya en América del Sur. Washington: WWF, 2006. Disponible en Internet: www.assets.panda.org/downloads/ managingthesoyboomspanish_57b6.pdf

GRAU, H.; AIDE, M. \& GASPARRI, N. Globalization and soybean expansion into 
semiarid ecosystems of Argentina. AMBIO A journal of the human environment, 2008, vol. $34, N^{\circ} 3$, p. 265-266.

GRUPO DE REFLEXIÓN RURAL (GRR). De los agro-negocios sin agricultores a una nueva cultura agraria: huecos en el debate sobre los transgénicos. Revista Theomai. Estudios sobre Sociedad, Naturaleza y Desarrollo, 2002, N 5, p. 1-20.

KAIMOWITZ, D.; THIELE, G. \& PACHE$\mathrm{CO}, \mathrm{P}$. The effects of structural adjustement on deforestation and forest degradation on lowland Bolivia. World Development, 1999, vol. 27, No 3, p. 505-520.

KAY, C. Rural development: from agrarian reform to neoliberalism and beyond. In: GWYNNE, R. \& KAY, C. (eds.) Latin America Transformed. Globalization and Modernity. Londres: Arnold, 1999, p. 271-304.

KHOLHEPP, G. Incorporação do espaço fronteriço do leste do Paraguai na esfera de influencia brasileira. In: POTTHAST, B. et al. El espacio interior de América del Sur. Geografía, historia, política, cultura. Frankfurt: Vervuert, 1999, p. 205-226.

LLACH, J. et al. La generación de empleo en las cadenas agroindustriales. Buenos Aires: Fundación Producir Conservando, 2004.

McMICHAEL, P. Global Food Poilitics. In: MAGDOFF, F. et al. Hungry for Profit. The Agribusiness Threat to Farmers, Food and the Environment. Nueva York: Monthly Review Press, 2000, p. 125-144.

MORELLO, J. y SOLBRIG, O. (ed.). Argentina, granero del mundo hasta cuando? La degradación del sistema agroproductivo de la Pampa Húmeda y sugerencias para su recuperación. Buenos Aires: Orientación Gráfica Editora, 1997.

OBSTCHATKO, E. La transformación económica y tecnológica de la agricultura pampeana. Buenos Aires: Ediciones Culturales Argentinas, 1988.

OZAWA, C. Science in environmental conflicts. Sociological Perspectives, 1996, vol. 39, No 2, p. 219-230.
OTERO, G. (ed.). Food for the Few. Neoliberal Globalism and Biotechnology in Latin America. Austin: University of Texas Press, 2008.

PAUL, H. \& STEINBRECHER, R. Hungry Corporations. Transnational Biotech Companies Colonise the Food Chain. Londres: Zed Books, 2003.

PENGUE, W. Cultivos Transgénicos. ¿Hacia dónde vamos? Buenos Aires: Lugar Editorial, 2000.

PENGUE, W. Agricultura industrial y transnacionalización en América Latina. ¿La transgénesis de un continente? Buenos Aires: PNUMA/GEPAMA, 2005.

PRINGLE, P. Food, Inc. Mendel to Monsanto the Promises and Perils of the Biotech Harvest. Nueva York: Simon \& Schuster, 2003.

RECA, L. y PARELLADA, G. El sector agropecuario argentino. Aspectos de su evolución, razones de su crecimiento reciente y posibilidades futuras. Buenos Aires: Editorial Facultad de Agronomía, 2001.

SANTOS, E. La internacionalización de la producción agro-alimentaria y el comercio agrícola mundial. Implicancias para el desarrollo agrícola y rural de América Latina y el Caribe. Buenos Aires: Grupo Editor Latinoamericano, 1992.

SCOBIE, J. Revolución en las pampas. Historia social del trigo argentino 1860-1910. Buenos Aires: Solar/Hachette, 1968.

SORJ, B. \& WILKINSON, J. Biotechnologies, multinationals and the agrofood system of developing countries. In: BONANNO, A. et al. (comp.). From Columbus to Conagra: the Globalization of Agriculture and Food. Kansas: The University Press of Kansas, 1994, p. 173-200.

SOLBRIG, O.; PAARLBERG, R. \& DI CASTRI, F. (ed.). Globalization and the Rural Environment. Harvard: Harvard University Press, 2001.

SLUTZKY, D. Los conflictos por la tierra en un área de expansión agropecuaria del 
NOA. La situación de los pequeños productores y los pueblos originarios. Revista Interdisciplinaria de Estudios Agrarios, 2005, №23, p. 59-100.

TEUBAL, M. Expansión del modelo sojero en la Argentina. De la producción de alimentos a las commodities. Realidad Económica, 2006, N²20, p. 71-94.
TRIGO, E. et al. Los transgénicos en la agricultura argentina. Una historia con final abierto. Buenos Aires: IICA- Ed. del Zorzal, 2002.

WARNKEN, P. The Development and Growth of the Soybean Industry in Brazil. Ames: lowa State U. Press, 1999.

YAPA, L. What are improved seeds? an epistemology of the Green Revolution. Economic Geography, 1993, vol. 69, № 3, p. 318-335. 